\title{
On Nonprimary Selectional Restrictions
}

\author{
Niina Zhang \\ zhang@zas.gwz-berlin.de
}

\begin{abstract}
This paper argues for non-primary c- and s-selectional restrictions of verbs in computing nonprimary predicatives such as resultatives, depictives, and manners. Our discussion is based both on the selection violations in the presence of nonprimary predicates and on the cross-linguistic and language-internal variations of categorial and semantic constraints on nonprimary predicates. We claim that all types of thematic predication are represented by an extended projection, and that the merger of lexical heads with another element, regardless of the type of the element, consistently has c- and s-selectional restrictions.
\end{abstract}

\section{Introduction}

Nonprimary predication includes resultative, depictive, manner, and path predication. This paper argues for non-primary c-selection and s-selection of verbs in integrating nonprimarypredication-denoting expressions into the clause structure.

$\mathrm{C}$-selection and s-selection are merger constraints on the complement of lexical head elements. The former is a categorial constraint, whereas the latter is a semantic constraint. Pesetsky (1982: 191, 1995) suggests that the former can be derived form the latter. However, as argued by Odijk (1997) and Speas (2000), c-selection is independent of s-selection. Language-internally, we find apparent synonyms that differ in what category their object can be. For example, ask can have a nominal or clausal object, while inquire can only have a clausal one.

(1) a. We asked $\{$ the time/what time it was .

b. We inquired $\{$ what time it was/ $*$ the time $\}$.

Cross-linguistically, we find apparent differences in the syntactic categories of objects of the same semantic type of verbs. For example, in English, the verbs that can have infinitive objects include hope, expect, need and want, but in French none of the counterparts of these takes an infinitive except that of want (Je voudrais partir).

Importantly, the observed c-selection of complement by lexical heads is not seen in non-complement elements. As shown in the following data (cited from Svenonius 1995), verbs have a strong influence over the finiteness of their clausal complement (2); however, they have no influence over the finiteness of their clausal subject (3).

(2) a. Jack $\{$ wished $/ *$ wanted $\}$ that he had never seen those magic beans.

b. Jack $\{$ wanted $/ *$ believed $\}$ for his mother to be proud of him.

c. Jack $\{$ regretted $/ *$ wished $\}$ trading the cow.

(3) a. That Pippi defeated the pirates \{defied comment/bothered the captain/sufficed to impress Mr. Nelson\}.

b. For Pippi to defeat the pirates would \{defy comment/bother the captain/suffice to impress Mr. Nelson\}.

c. Pippi's defeating the pirates \{defied comment/bothered the captain/sufficed to impress Mr. Nelson\}. 
Selection is merger of lexical elements with their complement. We call the standard selection primary selection, and c- and s-selectional restrictions of verbs primary selectional restrictions.

We will show that cross-linguistically and language-internally, nonprimary predicates are hosted by either complements or adjuncts, and the verbs are sensitive to the complementtype of nonprimary predicates. The sensibility is exhibited in, on the one hand, whether certain semantic or syntactic type of nonprimary predicates are allowed, and on the other hand, when they are allowed, whether the s- and c- selection of the verbs change in the presence of a nonprimary predicate.

If a nonprimary predicate is hosted in the complement of verbs, we call the merger of the verbs with this type of complement nonprimary selection, and the relevant categorial and semantic constraints on the merger non-primary selectional restrictions.

We make the following proposal. Unlike in the primary selection, the selected category of nonprimary selection is generally a semi-functional $\mathrm{xP}$, which is projected above a (lexical) XP (4), and the semantic types of the selected element in this case can be resultative, depictive, manner, path, etc. In addition, like $\mathrm{v}$, the functional $\mathrm{a}, \mathrm{n}$, and $\mathrm{p}$ assign a theta-role to their subject at Spec. Moreover, like v, the functional a, n, and p do not Caselicense the subject, and thus the subject has to be Case-licensed in the structure of the primary predicate, unless the language allows it to get a default case (Jang \& Kim, this volume, Schütze 2001). ${ }^{1}$

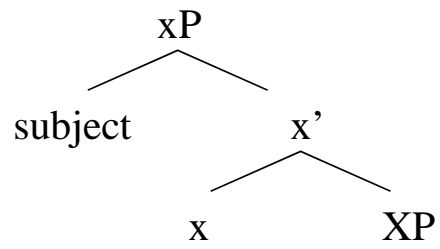

In our analysis, the $\mathrm{xP}$ for the complement-type of nonprimary predicates is merged with the verb of the primary predicate (5a), whereas the $\mathrm{xP}$ for the adjunct nonprimary predicates is an adjunct of the structure of the primary predicate (5b). As in primary selection, nonprimary selection occurs only in the complement-relation (5a).

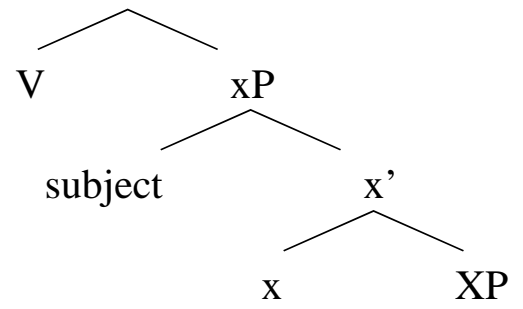

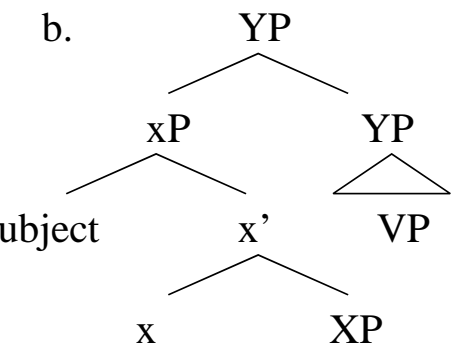

Note that our claim that verbs have both primary and nonprimary selectional restrictions does not imply that verbs can have two sisters (as in Carrier \& Randall 1992. See Bowers 1997 for arguments against Carrier \& Randall's approach). In (5a), xP is merged with the verb in $\mathrm{V}$, and then the newly-formed term is merged with another element. It is in this

\footnotetext{
${ }^{1}$ If $\mathrm{v}$ can case-license objects, which is in its complement, as assumed in Chomsky (1995), $\mathrm{x}$ in (4) should be able to license the case of XP. For instance, the Instrument and other cases of depictives in Russian may be licensed by x. Following the general idea of Richardson (this volume), we can further claim that the different cases may be related to different event-structure features of $\mathrm{x}$.
} 
derivational binary sense that nonprimary selection can bend primary one, but not the other way around (see section 6 and section 7).

Our XP hypothesis is different from Bowers' $(1993,2001)$ PrP theory in the following way. Although we not only adopt but also provide evidence for the occurrence of a functional projection in encoding a predication relation, we claim that the label of $\mathrm{PrP}$ is wrong. Theoretically, PrP is redundant, since its relation to $\mathrm{vP}$ is unclear in primary predication. Empirically, the category of PrP does not capture the interactions and variations observed in the literature and presented in this paper.

The paper is organized as follows. In section 2 we provide evidence to support the claim made by the PrP Theory that a thematic predication relation must be encoded by a functional projection, and adopt the unified analysis of the theta-role assignment to subjects proposed by the PrP Theory. In section 3, we present Chinese evidence to show that the assumed xP can be either complement of the verb or an adjunct. In section 4 we present crosslinguistic and language-internal variations of the category of complement-type nonprimary predicates, and argue that an extended projection rather than PrP can capture the facts. In section 5 we present cross-linguistic and language-internal semantic constraints on complement-type nonprimary predicates. We then discuss the violation of c- and s-selection of verbs in the presence of complement-type nonprimary predicates in section 6 . In section 7 , we argue for a syntactic account for the "Direct Object Restriction" on nonprimary predication, and account for one more instance of c-selection violation in the presence of nonprimary predicates. The paper is concluded in section 8 .

\section{A Thematic Predication Relation is Represented by $x P$}

In this section we discuss the projection of (4).

First of all, we need to distinguish thematic predication from non-thematic predication. In the former case, the theta-role of the subject is licensed after the subject is merged with a term which contains the predicate. Both primary and nonprimary predication belong to this case. Accordingly, we assume that event can be a subject, bearing an e-role. So predication of an event is a thematic predication. Non-thematic predication, however, is a derived predication relation, as in the relation between a topic and its comment, between a relative pronoun and the relative clause (Quine 1960, see Heim \& Kratzer 1998: 86), between the extra-nominative nominals and their sister clause (Heycock 1993, Heycock \& Doren 2001), etc. In the non-thematic predication relation, the theta-role of the subject is satisfied independent of the predication. Since non-thematic predication is computed later than a thematic predication, and thus is a derived rather than a basic predication relation, it is not discussed in this paper.

We argue that a thematic predication relation, regardless of whether it is a primary or non-primary predication relation, is represented by the extended projection xP.

Our notion of extended projection is different from Grimshaw's (1991). In Grimshaw's theory, "[A]n extended projection consists of a lexical head and its $\mathrm{X}^{\prime}$ projection plus all the functional projections above it." (Grimshaw 1994: 76) The notion of extended projection used here means the projection of a functional head which is merged with a lexical phrase, and the category features of the functional head and that of the lexical head are the same. An example of this extended projection is vP, which takes VP as complement. Both vP and VP are verbal, and thus they have the same category features. ${ }^{2}$

Three claims will be made: a functional projection is projected in nonprimary predication, an external argument is always merged at the Spec of this projection, and finally,

\footnotetext{
${ }^{2}$ If we adopt the theory of the Distributed Morphology, the so-called lexical phrases used generally and here may all be projections headed by "f-morphemes," which decide the category of the "l-morphemes." (cf. Marantz 1997)
} 
this projection shares its category features with its complement, and thus it is called "extended." In this section, we argue for the first two claims. The last claim will be argued for in section 4.

\subsection{The Projection of a Functional Category}

PrP Theory is right in claiming that a predication relation must be encoded by a functional projection. A direct argument for this is the obligatory alternation between the deconstruction, where the functional word de occurs, and the V-V construction, where the lexical heads of the two predicates are adjacent, in the integration of a nonprimary predicate (resultative/depictive/manner) in Chinese. In the following data, those in (6) are resultative constructions, those in (7) are depictive constructions, and those in (8) are manner constructions. ${ }^{3}$ The de-construction is seen in $(6 \mathrm{a} / 7 \mathrm{a} / 8 \mathrm{a} / 8 \mathrm{c})$, whereas the $\mathrm{V}-\mathrm{V}$ construction is seen in $(6 b / 7 b / 8 b)$. The nonprimary predicate follows the verb of the primary predicate (Vpri hence) in (6), (8b), (9b), and (9c), and it precedes Vpri in (7), (8a), (8c), and (9a). We will discuss the two orders in section 3.

(6) a. Wusong da de laohu liuxue le.

Wusong beat DE tiger bleed PRT

'Wusong beat the tiger so that it bled.'

b. Wusong da-si-le laohu.

Wusong beat-die-PRF tiger

'Wusong beat the tiger to death.'

a. Wusong ruanruan de pu-le yi ge dianzi.

Wusong soft DE lay-PRF one CL mattress

'Wusong laid a mattress soft.'

b. Wusong huo-zhuo-le laohu.

Wusong alive-catch-PRF tiger

'Wusong caught the tiger alive.'

(8) a. Akiu hen man de pao-le yi xiaoshi.

Akiu very slow DE run-PRF one hour

'Akiu ran very slowly for an hour.'

b. Akiu pao de hen man.

Akiu run DE very slow

'Akiu ran very slowly.'

c. Akiu man-pao-le yi xiaoshi.

Akiu slow-run-PRF one hour

'Akiu ran slowly for an hour.'

(9) a. Akiu hen zhengque de huida-le na ge wenti.

Akiu very correct DE answer-PRF that CL question

'Akiu answered that question very correctly.'

b. na ge wenti, Akiu huida de hen zhengque.

that CL question Akiu answer DE very correct

'That question, Akiu answered very correctly.'

\footnotetext{
${ }^{3}$ The abbreviations used in the Chinese examples are: EXP: experience aspect, PRF: perfect aspect, PROG: progressive aspect, PRT: sentence-final aspect particle, CL: classifier.

Pre-Vpri de and post-Vpri de are graphically different in Mandarin Chinese and phonologically different in some Chinese dialects. However, the different phonological or written forms do not mean that they are syntactically different. The different forms can be viewed as positional variants of the same category, as we often see in phonology. Crucially, the two forms of de occur in non-primary predication only, and they themselves do not have any semantic features to distinguish each other.
} 
c. na ge wenti, Akiu da-dui-le. that CL question, Akiu answer-correct-PRF

'That question, Akiu answered correctly.'

The alternation between the de-construction and the $\mathrm{V}-\mathrm{V}$ construction of nonprimary predication is further shown by the unacceptability of (10) below. (10a) is neither a V-V construction nor a de-construction, whereas (10b) has both de and a V-V form. Both sentences are intended to encode a resultative meaning.
a. *Baoyu da laohu liuxue.
Baoyu beat tiger bleed
b. *Baoyu da si de laohu
Baoyu beat die DE tiger
Intended: 'Akiu beat the tiger to death.'

In our analysis, the head of xP in (4) is realized either by de or a head raising from the nonprimary predicate (XP). ${ }^{4}$ De always attaches to the right of the leftmost verbal element at $\mathrm{PF}$, as argued in Zhang (2001a).

\subsection{The Position where External Arguments are Merged}

$\operatorname{PrP}$ Theory is right in the following unification: the theta-role of subjects is assigned to the Spec of a functional head in both primary (Hale \& Keyser, Marantz, Kratzer, Harley, etc.) and nonprimary predication. Not all functional heads can have a theta-relation with another element: the semi-functional head $\mathrm{v}$ can whereas the pure functional ones such as I, C, D, etc., cannot.

An argument for the independent structural position for the external argument of nonprimary predicate is that in both resultative and depictive constructions, there are cases where argument-sharing is absent. In the following data, the underlined part, which is the subject of the nonprimary predicate, does not share with any argument of the primary predication.

(11) a. $\operatorname{John}_{\mathrm{i}}\left[\mathrm{t}_{\mathrm{i}}\right.$ ran [the pavement thin]].

b. $\quad$ Akiu $_{\mathrm{i}}\left[\mathrm{t}_{\mathrm{i}} \mathrm{ku}\right.$ de [shoujuan dou shi le]].

Akiu cry DE handkerchief also wet PRT

'Akiu cried so that the handkerchief became wet.'

(12) a. Baoyu $_{\mathrm{i}}\left[\mathrm{t}_{\mathrm{i}} \mathrm{da}\right.$ de Daiyu [shou dou teng le]]. (resultative) ${ }^{5}$

Baoyu beat DE Daiyu hand also painful PRT

'Baoyu beat Daiyu so that his Baoyu $_{\text {own hand was painful.' }}$

b. Akiu $[$ xue linlin de $]\left[t_{i}\right.$ chi-le na tiao yu]. (obj-related depictive)

Akiu blood drip DE eat-PRF that CL fish

'Akiu ate that fish, the blood of which dripped.'

c. $\quad \mathrm{Akiu}_{\mathrm{i}}$ [yanlei wangwang de] [ $\mathrm{t}_{\mathrm{i}} \mathrm{ku}$-le yi shangwu]. (subj-related depictive)

Akiu tear full DE cry-PRF one morning

'Akiu cried for one morning, (in a way that) his tears were full (in his eyes).'

Data like (12), however, have the constraint that the overt subject of the secondary predicate must have a part-whole relation with an argument of the Vpri. In (12a), the subject

\footnotetext{
${ }^{4}$ Sybesma (1999) makes a similar proposal for resultative constructions.

${ }^{5}$ I thank Zo Xiu-Zhi Wu for helping me with the Chinese example (12a). Korean data similar to (12) can be found in Kim \& Maling (1997).
} 
of Vpri, Ваоуu, is an inalienable possessor of shou 'hand', which is the subject of the secondary predicate teng 'painful'. (13a) is unacceptable because no such relation occurs between the subject of the secondary predicate, caidao 'knife', and any argument of the Vpri. In (12b), xue 'blood' is the subject of the depictive linlin 'drip', and it has a part-whole relation with the object of the Vpri, na tiao yu 'that cl fish'. (13b) is not acceptable, because there is no part-whole relation between the overt subject of the depictive, tian 'sky', and any argument of the Vpri.
a. $\quad$ *Akiu qie de rou caidao dou dun le. Akiu cut de meat knife even blunt prf
b. *na zhi laohu tian hei de chi le yi kuai rou. that cl tiger sky dark de eat prf one cl meat

The independent overt subjects of the nonprimary predicates require an independent structural position, and theta-role. We thus assume that the theta-role assigner of subjects is consistently a semi-functional head $(\mathrm{v} / \mathrm{a} / \mathrm{n} / \mathrm{p})$. The subject of a secondary predicate is a PRO if argument sharing occurs (Hornstein \& Lightfoot 1987, Bowers 1993, 2001), assuming that each nominal has only one $\theta$-role. ${ }^{6}$ Manners are predicates of events (e).

\section{Adjunct xP \& Complement xP}

In this section we discuss the contrast between (5a) and (5b). Cross-linguistically and language internally, nonprimary predicates are hosted by either complements of verbs or adjuncts of the primary predicate. It is generally assumed that subject-oriented depictives are hosted by adjuncts, whereas resultatives are hosted in complement of verbs in English (Bowers 1993, 2001, Hornstein \& Lightfoot 1987, Larson 1991, etc.).

In Chinese, postverbal nonprimary predicates are complements of verbs (Huang 1988, Li 1998, also cf. Ernst 1996), whereas preverbal ones are hosted by an adjunct, regardless of the semantic type of the relevant nonprimary predicate (manner or resultatives). One argument for the contrast is seen in extraction (also Li 1998). Extraction from a nonprimary predicate which follows the Vpri is possible, as shown in (14), whereas extraction from a nonprimary predicate which precedes the Vpri is not possible, as shown in our topicalization and relativization data in (15) and (16).

(14) a. Daiyu chaoxiao de Baoyu zhongyu fangqi-le na ge niantou.

Daiyu mock DE Baoyu finally give.up-PRF that CL idea

'Daiyu mocked Baoyu so that finally Baoyu gave up that idea.'

b. na ge niantou, Daiyu chaoxiao de Boauy zhongyu fangqi-le. (topicalization) 'That idea, Daiyu mocked Baoyu so that finally Baoyu gave up.'

c. na ge [RC Daiyu chaoxiao de Baoyu zhongyu fangqi-le de] niantou (relativization) 'the idea that Daiyu mocked Baoyu so that finally Baoyu gave up'
a. $\quad$ Akiu $_{i}$ [xue linlin de] $\left[\mathrm{t}_{\mathrm{i}}\right.$ chi-le na tiao yu].
Akiu blood drip DE eat-PRF that CL fish
'Akiu ate that fish, the blood of which dripped.'
b. *xue, Akiu linlin de chi-le na tiao yu.
c. $\quad *[$ RC Akiu linlin de chi-le na tiao yu de $] \underline{x u e}$

(obj-related depictive)

(topicalization)

(relativization)

\footnotetext{
${ }^{6}$ Hornstein (1999) claims that control is movement and a nominal can have more than one theta role, a change of the Theta-Criterion. Kayne (2001) also claims that control is derived by movement. However, Kayne's analysis does not require the change of the Theta-Criterion. We are open to any analysis of control, so long as both the subject of a nonprimary predicate and that of a primary predicate need a theta-role.
} 
(16) a. Akiu $\mathrm{i}_{\mathrm{i}}$ [yanlei wangwang de] [ $\mathrm{t}_{\mathrm{i}} \mathrm{ku}$-le yi shangwu]. (subj-related depictive)

Akiu tear full DE cry-PRF one morning

'Akiu cried for one morning, (in a way that) his tears were full.'

b. *yanlei, Akiu wangwang de ku-le yi shangwu. (topicalization)

c. $*$ [RC Akiu wangwang de ku-le yi shangwu de] yanlei (relativization)

Another argument for the contrast between preverbal and postverbal nonprimary predicates is that different types of preverbal nonprimary predicates are structurally ordered in the hierarchy which is also seen in adverbials.

First, multiple nonprimary predicates are ordered. When multiple preverbal depictives co-occur, we see mirror images of the orders in English and Chinese: In English, the order is object-oriented depictive - subject-oriented depictive (Carrier and Randall 1992), while in Chinese the order is just opposite; however, in both languages, object-oriented depictives are closer to Vpri than subject-oriented ones, as shown in the following:
a.
$\mathrm{V}$ depictive $_{\mathrm{obj}}$ depictive $_{\mathrm{sbj}}$
(English)
b. depictive $_{\text {sbj }}$ depictive $_{\text {obj }} \mathrm{V}$
(Chinese)

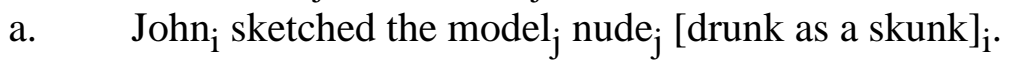

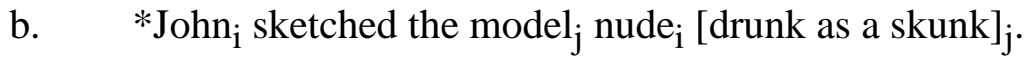
a. $\quad$ Akiu $_{\mathrm{i}}$ yukuai $_{\mathrm{i}}$ de rere $\mathrm{j}_{\mathrm{j}}$ de he le [na wan cha $]_{\mathrm{j}}$.
Akiu happy DE hot DE drink PRF that bowl tea
'Akiu drank that bowl of tea hot happy.'
b. $\quad *$ Akiu $_{\mathrm{i}}$ rere $_{\mathrm{j}}$ de yukuai ${ }_{\mathrm{i}}$ de he le [na wan cha $]_{\mathrm{j}}$.
Akiu hot DE happy DE drink PRF that bowl tea

In (18), the depictive nude is closer to the Vpri sketched than the depictive drunk as a skunk. In the acceptable (18a), the subject of nude is co-referential with the model, which is the object of the Vpri, and the subject of drunk as a skunk is co-referential with John, which is the subject of the Vpri. (18b), with the opposite co-indexing, is unacceptable. Thus the objectoriented depictive is closer to the Vpri than the subject-oriented one. In (19), there are also two depictive predicates, rere 'hot' and yukuai 'happy'. In both sentences the subject of rere is co-referential with na wan cha 'that bowl of tea', which is the object of the Vpri he 'drink', and the subject of yukuai is co-referential with Akiu, which is the subject of he. Rere is closer to he 'drink' than yukuai in the acceptable (19a), whereas it is the other way around in the unacceptable (19b). Like (18), (19) also shows that the object-oriented depictive is closer to the Vpri than the subject-oriented one.

The pattern of the orders is similar to that of adverbials. In the following data ((21) is from Hornstein 2001: 116) the adjunct which has a dependency relation with the object of the matrix verb must be ordered closer to the matrix verb than the adjunct which has a dependency relation with the subject of the matrix verb.

(20)a. $\mathrm{John}_{\mathrm{i}}$ arrested $\mathrm{Bill}_{\mathrm{j}}$ [for $\mathrm{PRO}_{\mathrm{j}}$ driving his car too fast] [after $\mathrm{PRO}_{\mathrm{i}}$ leaving the party]

b. ??John ${ }_{i}$ arrested Bill ${ }_{j}$ [after $\mathrm{PRO}_{\mathrm{i}}$ leaving the party] [for $\mathrm{PRO}_{\mathrm{j}}$ driving his car too fast]

(21)a. $\mathrm{John}_{\mathrm{i}}$ bought Moby Dick $\mathrm{j}$ [for Mary to review $\mathrm{e}_{\mathrm{j}}$ ][PRO $\mathrm{PR}_{\mathrm{i}}$ to annoy Sam]

b. ${ }^{*} \mathrm{John}_{\mathrm{i}}$ bought Moby Dick $\mathrm{j}_{\mathrm{j}}\left[\mathrm{PRO}_{\mathrm{i}}\right.$ to annoy Sam][for Mary to review $\left.\mathrm{e}_{\mathrm{j}}\right]$

There is no doubt that the non-finite clauses above are adverbials. Hornstein (2001: 97) claims that the adjunct which has a dependency relation with the object of the matrix verb is adjoined lower than the adjunct which has a dependency relation with the subject of the 
matrix verb. This difference in height indicates that the former has a closer structural relation to the matrix verb than the latter. In the linear order, the former is also closer to the matrix verb than the latter. The order restriction in (18) and (19) indicates that like the adverbials in $(20) /(21)$, object-oriented and subject-oriented pr-Vpri nonprimary predicates are ordered in a certain structural hierarchy. In Hornstein \& Lightfoot (1987: 27), the functional phrase hosting a subject-oriented depictive is a VP-adjunct, whereas the functional phrase hosting an object-oriented depictive is a V'-adjunct. The Chinese data in (18) and (19) are compatible with this distinction.

Second, the interactions with adverbs show the structural order of different types of depictives. For instance, subject-oriented pre-Vpri nonprimary predicates can occur to the left of the adverb like 'immediately,' while object-oriented ones cannot, as shown in (22):
a. Akiu (like)
gaoxing de (like)
chang le yi shou ge.
Akiu immediately glad DE immediately sing PRF one CL song
'Akiu sang a song glad (immediately).'
b. Akiu (like) rere de (*like) he le yi bei cha.
Akiu immediately hot DE immediately drink PRF one cup tea
'Akiu drank a cup of tea hot (immediately).'

This restriction shows that the $\mathrm{xP}$ hosting the object-oriented depictive is ordered lower than both the adverb and the xP hosting the subject-oriented depictive on the adverbial hierarchy, and thus has a closer structural relation with the Vpri.

The similarity of the order-patterns of depictives to the order-patterns of adverbials, and the interactions with other adverbs suggest that the xP hosting pre-Vpri nonprimary predicates has properties of adverbials. This order fact supports our claim that XPs which host pre-Vpri nonprimary predicates have an adjunct status in their integration into the structure of primary predication.

A remaining issue is what syntactic operation enables co-reference between the null subject of a pre-Vpri nonprimary predicate and an argument of Vpri. In other words, what are the syntactic representations of the so-called subject-orientation or object-orientation of a preVpri nonprimary predication. Following Hornstein \& Lightfoot's (1987) analysis of depictives, I assume that the pre-Vpri nonprimary predication constructions have a controlinto-adjunct structure. In other words, the null subject of a pre-Vpri nonprimary predicate is a PRO, controlled by an argument of the relevant Vpri.

\section{The Category Constraints on the Complement-Type Nonprimary Predicates}

In this section we argue that $\mathrm{x}$ in $(4) /(5)$ shares the same categorial features with their complement and when the verb in $\mathrm{V}$ is merged with the $\mathrm{xP}$ in $(5 \mathrm{a})$, it shows c-selectional restrictions. We have three arguments:

\subsection{Cross-Linguistic Variations}

Category constraints on nonprimary predicates are language-specific. For instance, nonmotion verbs allow complement-type nonprimary predicates to be PPs in English but not in Chinese. Recall that resultatives in English and post-verbal nonprimary predicates in Chinese are of complement-type. The resultative in (23), regardless of whether the Vpri is motion verb or not, are all PPs. In (24), however, the preposition xiang 'to' can occur with a motion verb, such as kai 'run' in (24a) and zou 'walk' in (24b), but not other verbs (24c).

(23) a. The children ran into the woods.

b. Peter cut the meat into slices. 
c. The vase broke into several pieces.

d. Bill beat John to death.

a. zhe liang huozhe zheng kai xiang Monggu.

this CL train PROG run to Mongolia

'This train is running to Mongolia.'

b. tamen zhengzai zou-xiang siwang.

they PROG walk-to death

'They are walking towards death.'

c. *Wusong da de laohu xiang siwang.

Wusong beat DE tiger to death

In addition, VP resultatives are allowed in Chinese (6), Japanese (Washio 1997), and Saramaccan (Veenstra 1996), but not English (25a) (Larson 1991, Dechaine 1993).

(25) a. *John shot Mary die.

b. John shot Mary dead.

Furthermore, postverbal manners are consistently APs (or DegPs) in Chinese, whereas they are AdvPs and PPs in English.

(26) a. Bill checked that room with a great care.

b. Bill checked that room carefully.

(27) a. na jian fangzi, Akiu jiancha de hen zixi.

that CL room Akiu check DE very careful

'That room, Akiu checked carefully.'

b. *na jian fangzi, Akiu jiancha de yong xixin.

that $\mathrm{CL}$ room Akiu check DE with carefulness

In certain cases, manners can be either AP or AdvP in English (Washio 1997: 17):

(28) a. He tied his shoelaces tight/tightly.

b. He tied his shoelaces loose/loosely.

(29) a. He spread the butter thick/thickly.

b. He spread the butter thin/thinly.

Finally, in the Chinese de construction, resultatives can be a full clause (Li 1998). In our following data, the post-Vpri resultative (the underlined part) is a full clause. In (30b), the focused embedded object, fan 'meal,' is preposed within the resultative clause.

a. Baoyu qi-de Daiyu dou bu xiang chi fan le.

Baoyu anger- DE Daiyu even not want eat meal PRT

'Baoyu angered Daiyu so that Daiyu even did not want to eat meals.'

b. Baoyu qi-de Daiyu lian fan dou bu xiang chi le.

Baoyu anger- DE Daiyu even meal even not want eat PRT

'Baoyu angered Daiyu so that Daiyu even did not want to eat meals.'

When resultatives are in a full clause, we claim that the verb in $\mathrm{V}$ is merged with a clause, although the predication relation internal to this resultative clause is still encoded by an $\mathrm{xP}$, an agentive $\mathrm{vP}$ in (30). 


\subsection{Language-Internal Variations}

Language internally, different semantic types of verbs have different category constraints on their secondary predicates. In Chinese, while verbs of beating allow their resultatives to be a VP (6), verbs of creation require their resultatives to be an AP (or DegP) only. In the unacceptable (31c), the postverbal resultative is headed by the verb $j i$ 'cram'. This cannot be accounted for semantically.
a. Naxie zi, Baoyu xie de hen da. those character Baoyu write DE very big 'Those characters, Baoyu wrote very big.'
b. Baoyu xie-da-le haojige zi. Baoyu write-big-PRF several characters 'Baoyu wrote several characters big.'
c. *Naxie zi, Baoyu xie de ji zai yiqi le. those character Baoyu write DE cram at together PRT

The contrast that PP-nonprimary predicates can occur with motion verbs but not other verbs in Chinese, shown in the previous subsection, is another instance of language-internal category-constraint on nonprimary predicates.

\subsection{The Correlation between Shared Category Constraints and Shared Syntactic Properties}

Like in primary c-selection, verbs which have the same category constraint on their nonprimary predicates share syntactic properties. In Chinese, certain types of verbs require their complement-type nonprimary predicates to be APs. For these verbs, their objects must be preposed in the construction where a nonprimary predicate occurs to the right of $d e$. This is seen in verbs of change of state (32a vs. 32b), transference (33a vs. 33b), and creation (34a vs. $34 b)$, in contrast to other types (35). (Those in (32b), (33b), and (34b) are acceptable in a relative clause reading, irrelevantly) Relevantly, postverbal manners must be APs, and objects must also be preposed in the de-construction (36). The c-sentences show that the preposing can also land to the right of the subject, preceded by the functional word $b a$.

(32) a. na zhi qianbi, Akiu xue de hen jian.

that CL pencil Akiu cut DE very sharp

'That pencil, Akiu cut sharp.'

b. *Akiu xue de na zhi qianbi hen jian.

c. Akiu ba na zhi qianbi xue de hen jian.

a. na jian chenshan, Baoyu mai de youdianr da.

that CL shirt Baoyu buy DE somehow big

'That shirt, Baoyu bought somehow over-sized.'

b. *Baoyu mai de na jian chenshan youdainr da.

a. Naxie zi, Baoyu xie de hen da. (=31a)

those character Baoyu write DE very big

'Those characters, Baoyu wrote very big.'

b. $\quad$ *Baoyu xie de naxie zi hen da.

Baoyu da de na ge xiaohai hen shangxin. (cf. 6a, $d a$ allows VP-resultative)

Baoyu beat DE that CL child very sad

'Baoyu beat that child so that the child became very sad.'

a. na shou shi, Akiu nian de feikuai.

that CL poem Akiu read DE fast

'That poem, Akiu read fast.' 
b. *Akiu nian de na shou shi feikuai.

c. Akiu ba na shou shi nian de feikuai.

See Appendix for more discussion of this obligatory object-preposing.

\subsection{Accounting for the Category Sensitivity of V to X}

PrP Theory cannot explain why verbs are sensitive to the category of their complement-type secondary predicate. Our (5a) is repeated here as (37a), and its counterpart in PrP Theory is (37b):

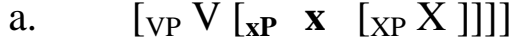

$$
\begin{aligned}
& \text { b. [ } \left.\left.{ }_{\mathrm{vP}} \mathrm{V}[\operatorname{PrP} \operatorname{Pr}[\mathrm{XP} X]]\right]\right]
\end{aligned}
$$

In (37b), PrP either has no category feature or is like a Small Clause, the category of which is unrelated to the complement XP. If the features of a projection must be that of the head exclusively (Lóbez 2001), the dependency between V and X, as shown in the previous three subsections, is unexpected. The sensibility indicates that the predication-encoding projection is an extended projection and thus shares the category features with the complement. In (37a 15a), the verb in V nonprimarily c-selects $\mathrm{xP}$, and $\mathrm{xP}$ and $\mathrm{XP}$ have the same category features.

The only argument for the absence of a category feature of Pr seen in the PrP Theory is that predicates in different categories can be coordinated, as shown in (38).

(38) I consider Fred crazy and a fool.

However, single-conjunct agreement (Aoun, Benmamoun \& Sportiche 1994, 1999, Munn 1999), independent phi-feature of a conjunction construction for binding (Borsley 2001), and the categorial-sensitivity of Chinese conjunctions (Lü et al. 1980), as well as the unlike-category coordination discussed in the PrP Theory, all suggest that a conjunction itself may have formal features. Thus the coordination issue can have an alternative account.

\section{The Semantic Constraints on the Complement-Type Nonprimary Predicates}

In this section we argue that the verb in $\mathrm{V}$ in (5a) nonprimarily s-selects $\mathrm{xP}$.

PrP Theory provides no account for the following semantic facts. Our nonprimary sselection, however, can cover them.

\section{$\underline{5.1 \text { Cross-Linguistic Variations }}$}

Semantic constraints of certain semantic types of verbs on their nonprimary predicates are language-specific. For instance, verbs of change of state allow object-oriented depictives in English (Rapoport, To appear), but not in Chinese. Object-oriented secondary predicates with such verbs must be resultative in Chinese, regardless of whether they are pre- (40) or postverbal (41):
a. Jones cut $[\text { the bread }]_{\mathbf{i}}$ hot $_{\mathbf{i}}$.
b. Jones fried [the potatoes $]_{i}$ raw $_{\mathbf{i}}$.
c. Jones froze $[\text { the juice }]_{i}$ fresh $_{\mathbf{i}}$.
d. Jones boiled [the lobsters $]_{i}$ alive . $_{\text {. }}$

a. Akiu $\left\{{ }^{*} x i x i / l a n l a n\right\}$ de zhu-le yi guo miantiao.

Akiu thin/pasty DE cook-PRF one pot noodle

'Akiu cooked a pot of noodle pasty.' 
b. Akiu \{*honghong/jianjian\} de xue-le yi zhi qianbi.

Akiu red/sharp DE cut-PRF one CL pencil

'Akiu cut the pencil sharp.'

(41) a. na guo miantiao, Akiu zhu de hen $\{* x i / l a n\}$.

that pot noodle Akiu cook DE very thin/pasty

'That pot of noodles, Akiu cooked very pasty.'

b. na zhi qianbi, Akiu xue de hen $\{*$ hong/jian $\}$

that CL pencil Akiu cut DE very red/sharp

'That pencil, Akiu cut sharp.'

In Larson (1991), object-oriented depictives are hosted in the complements of verbs in English. We claim that verbs of change of state in the two languages have different nonprimary s-selections.

On the other hand, in neither English nor Chinese activity primary predicates allow object-oriented depictives, whereas in Russian they do (see section 2.2 of Richardson, this volume). In (42), the subject of drunk must take the matrix subject John as antecedent. In the Chinese examples in (43), the pre-Vpri man-tou da-han 'in a sweat' must be a subjectoriented depictive (43a) and the post-Vpri man-tou da-han must be resultative (43b). Thus as in English, the nonprimary predicate occurring with the activity primary predicate does not have an object-oriented depictive reading. In contrast, in the Russian example (44), the depictive p'janogo 'drunk' can be object-oriented in the presence of the activity verb tolknula 'pushed.'

(42) a. $\mathrm{John}_{\mathrm{k}}$ pushed Bill drunk $_{*_{\mathrm{i} / \mathrm{k}}}$.

b. $\quad \mathrm{John}_{\mathrm{k}}$ chased Betty $\mathrm{drunk}_{\mathrm{i}}$ $_{\mathrm{i} / \mathrm{k}}$.

a. Baoyu man-tou da-han de zhui Daiyu.

Baoyu whole-head big-sweat de chase Daiyu

'Baoyu chased Daiyu in a sweat ${ }_{\text {Baoyu.' }}$,

b. Baoyu zhui de Daiyu man-tou da-han.

'Baoyu chased Daiyu so that Daiyu was in a sweat.'

Ja tolknula Ivana $\mathrm{i}_{\mathrm{i}} \quad \mathrm{p}^{\prime} \mathrm{janogo}_{\mathrm{i}} . \quad$ (= Richardson, this volume (24))

I pushed Ivan-ACC drunk-ACC

The above contrast shows that the semantic constraints of activity primary predicates on nonprimary predicates are different in English/Chinese and Russian.

\subsection{Language-Internal Variations}

Language internally, different semantic types of verbs have different semantic constraints on their secondary predicates. In Chinese, unlike verbs of change of state (41), verbs of transference allow postverbal depictives rather than resultatives. This is shown in both (45) and the above (33a).

Na liang che, Baoyu zhu de tai jiu le.

that CL car Baoyu rent DE too old PRT

OK: 'That car, Baoyu rented when it was too old.'

Not: 'That car, Baoyu rented and thus it became too old.'

\section{$\underline{5.3 \text { A Cross-Linguistic Semantic Constraint }}$}

In primary s-selection, certain semantic types of verbs resist certain semantic type of complements. For instance, verbs such as eat, devour, drink, sip, taste do not s-select a 
question. Similarly, telic verbs/verbal-complexes, which intrinsically encode a measure possibility, in the sense of Vanden Wangaerd (2001), resist resultatives. This generalization can cover the following five facts.

First, unaccussatives generally do not take resultatives.

(46) a. *The river froze the fish dead.

b. $\quad *$ The ice melted the floor clean.

The same constraint on Chinese is noted by $\mathrm{Gu}$ (1992). Our de-construction in (47a) and the corresponding V-V construction in (47b) show this constraint:
a. *Hu-shui dong de yu dou si le.
lake-water froze DE fish even die PRT
b. *Hu-shui dong-si-le yu.
lake-water froze-die-PRF fish

According to Pustejovsky (1991: 76), such verbs already encode a change-of-state meaning. In Hale \& Keyser's (1993, and their later works) analysis, such verbs are derived by a conflation of a null verb with a result-denoting Adjective, as illustrated in (48).

a. The screen cleared.

b.

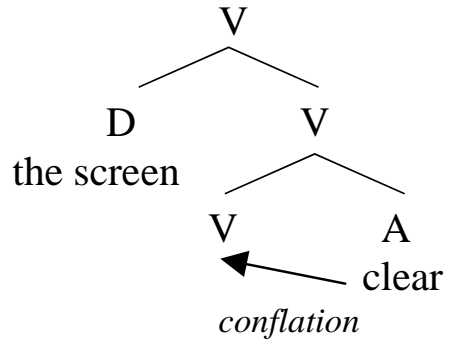

Second, unlike depictives, resultatives cannot stack. Resultatives do not co-occur with resultatives, while depictives can co-occur with depictives, as shown in (49). The restriction in English is discussed in Simpson (1983) and Rothstein (1985). The same contrast is observed in Chinese, as shown in (50).

(49) a. *John kicked the door open to pieces.

(resultative)

b. They ate the meat raw tender.

(50) a. *Akiu da de Baoyu haotaodaku shou le shang.

Akiu hit DE Baoyu cry.loudly suffer PRF wound

b. Akiu huoshengsheng de xinglixingqi de chi le na tiao yu.

(resultative)

Akiu alive DE stinky DE eat PRF that CL fish

(depictive)

'Akiu ate that fish alive stinky.'

If an event can be delimited only once and a resultative delimits the event encoded by the primary predication, the ban of the multiple resultatives is explained.

Third, Romance verbs do not allow resultatives in general. The following Catalan examples are cited from Mateu (this volume, section 4):

(51) a. Joe kicked the door open.

b. *El Joe colpejà la porta oberta.

the Joe kick.PST.3.SG the door open 
(52) a. Joe kicked the dog into the bathroom.

b. *El Joe colpejà el gos a dins el bany.

the Joe kick.PST.3.SG the dog inside the bathroom

In order to account for Talmy's (1991) typological distinction between 'satelliteframed languages' such as English and German and 'verb-framed languages' such as Catalan and Spanish, Mateu argues that in verbs of the latter group, a telic path has been conflated, and thus semantically like in the case of unaccusatives, a telic information has been encoded. The following contrast between English and Catalan (Mateu's (52)) shows that there is a conflation of Motion and Manner in the English verb dance (53a), whereas there is conflation of Motion and Path in the Catalan verb entrà (53b):

(53) a. The boy danced into the room.
b.
El noi entrà
l'habitació ballan.
the boy went-into LOC.PRP the room dancing

Unlike manners and like resultatives, paths delimit events. Since an event cannot be delimited more than once, verbs such as entrà, which contain information of a path, cannot occur with a resultative.

Fourth, Chinese V-V compounds where the second V is a telic directional verb do not allow resultatives.
a. *Akiu zou-jin de na jian maocao-peng dou ta le. Akiu walk-enter DE that CL straw-hut even collapse PRT
b. *Akiu yun-lai de na ge xiangzi dou po le.
Akiu transport-come DE that CL box even broken PRT

The Chinese V-V compounds can be viewed as an analytic case of Romance entrà in (53b), where a path is implicitly conflated. In neither case, a resultative is allowed.

Finally, Russian verbs generally do not allow resultatives (exceptions are seen in Richardson, this volume (38)). Vanden Wangaerd (2001) convincingly argues that a resultative is more adequately seen as a measure than an "ending up-with" state. Specifically, resultatives function like classifiers of nominals in their ability to measure a mass-like activity. ${ }^{7}$ Strigin (2001), on the other hand, shows that the Russian perfect aspect, which marks bounded events and is required in the presence of a quantized internal argument, has intrinsically encoded telicity. However, this telicity differs from what has generally been claimed in English in that no end-point is necessarily reached with respect to the quantized internal argument. Both Strigin and Van Wangared conclude that telicity is not related to end point. Strigin further argues that the absence of resultatives in Russion is accounted for by the presence of this telicity in the aspect of Russian verbs.

Our nonprimary s-selection accounts for all of the five observations in a unified way.

\section{The Violation of S-/C-Section of Verbs in the Presence of Nonprimary Predicates}

The c- and s-selection of the verb in primary predicate can be changed in the presence of a complement-type nonprimary predicate, as in (55b).

a. Freddy cried.

\footnotetext{
7 The distinctions among "measure out," "delimit," and "measurable to the event" are discussed in a different context in Zhang (1997 section 5.2.1). The notion "measurable" is similar to the notion "decomposable" suggested by a reviewer of Van Wangared (2001) (p. 76).
} 
b. Freddy cried the handkerchief wet.

In this section we argue that this is the result of the interaction between two types of selection: a primary one and a nonprimary one. Specifically, it is the result of the early merge of xP with the verb. We propose our analysis of the violation in 6.1 and point out the inadequacies of some other approaches in section 6.2.

\section{$\underline{6.1 \text { A Selection Approach to Selection Violations }}$}

On the one hand, it has been argued that English resultatives are hosted in complement of verbs (Hoekstra 1988, Roberts 1988:705, Larson 1991, Bowers 1993, 1997, 2001, Levin \& Rappaport Hovav 1995:49, etc.). On the other hand, unergatives such as ran neither c-select a clause nor s-select a proposition. In (56a), the resultative himself tired as a nonselected element occurs as complement, a violation of the selection of the verb. Similarly, cry neither c-select a clause nor s-select a proposition. In (55b), the resultative the handkerchief wet as a nonselected element occurs as complement, a violation of the selection of the verb. The selection violation is also seen in transitives, such as wipe in (56b), if wipe selects neither a clause nor an AP. Selection violation is also seen in data like (56c), where the transitive verb drank cannot have an internal argument.
a. He ran himself tired.
b. John wiped the table clean.
c. John drank (*the wine) his guests under the table.

Hoekstra $(1988,1992)$ makes a generalization that any activity verb may be turned into an accomplishment by adding a resultative small clause to it. What Hoekstra's generalization tells us is that selectional restrictions of verbs can be systematically violated, in the presence of resultatives. Considering a broader range of data shown in the previous sections, we see that selection of verbs can be systematically violated in the presence of a nonprimary predicate of the complement-type. As we know, the theory of selection has been argued for without considering of nonprimary predication. On the other hand, the complement analysis of English resultatives and Chinese post-verbal nonprimary predicates in general, ignores the selectional restrictions of the Vpri. In order to keep the empirical force of both considerations, i.e., selection and the analysis of the nonprimary predicates, we claim that verbs have nonprimary s- and c-selection, in addition to their hitherto recognized s- and cselection.

Independent arguments for the hypothesis of nonprimary selection have been shown in the previous sections, i.e., verbs are categorially and semantically sensitive to their nonprimary predicates, cross-linguistically and language-internally.

As expected, the two types of selection interact. The interaction accounts for the selection violation. Importantly, if a nonprimary predicate is not hosted by the complement of a verb, there is no nonprimary selection and thus the c- and s-selection of the verb cannot be violated, as shown in (57) and (58). In (57b), the manner quickly is not hosted by the complement of devoured, the c-selection of a nominal remains obligatory. Similarly, in (58b), the subject-oriented depictive naked is not hosted by the complement of inquired. The cselection is violated in (58a), so is in (58b) (cf. (1b)).

(57) a. We devoured $*$ (the cake).

b. We devoured $*$ (the cake) quickly.

(58) a. *John inquired the time.

b. *John inquired the time naked. 
The interaction between the two types of selection can be analyzed as follows. In our (5a), a verb in $\mathrm{V}$ merges with $\mathrm{xP}$ before an internal argument is merged. We claim that since nonprimary c- and s-selections are satisfied earlier, they may interact with primary c- and sselections: an internal argument of Vpri can be absorbed (56c), and the case of the overt subject of the nonprimary predicate gets licensed (56a). Specifically, in the presence of xP at a certain derivational step, a verb is merged with the $\mathrm{xP}$ directly. If both the $\mathrm{c}$ - and snonprimary selectional restrictions are satisfied in this merger, the new term is then able to merge with another element. If the subject of the $\mathrm{xP}$ is a PRO, as in (56b), its overt controller will be integrated, following the Minimal Distance Principle (Rosenbaum 1970) (this analysis is compatible with any treatment to the Case of PRO). If there is no PRO, as in (56a) and (56c), the overt subject in $\mathrm{xP}$ needs to be Case-licensed in the same way as in the ECM structure (Bowers 1993, 2001). The $\mathrm{x}$ in this case, like $\mathrm{v}$ in primary predicate, cannot Caselicense its theta-related subject. The nearest Case-licensor for the nonprimary subject is the $\mathrm{v}$ of the primary predicate. As generally assumed, $\mathrm{v}$ can only license Accusative Case in English. Thus the subject of the nonprimary predicate can only have Accusative Case, as in (56a).

On the other hand, since the primary predicate can only license one Accusative Case, if it Case-licenses the overt subject of the nonprimary predicate, it cannot license another overt internal argument of its own. This explains the absence of an object in (56c). ${ }^{8}$

One remaining issue is how to explain (12a), repeated here as (59), where both the object of Vpri and the overt subject of the resultative occur.

Baoyu $_{\mathrm{i}}\left[\mathrm{t}_{\mathrm{i}}\right.$ da de Daiyu [shou dou teng le]].

Baoyu beat DE Daiyu hand also painful PRT

'Baoyu beat Daiyu so that his ${ }_{\text {Baoyu }}$ own hand was painful.'

Recall that an inalienable possession relation between the subject of the nonprimary predicate and an argument of the primary predicate is required in such construction (section 2.2). We claim that the construction in (59) is derived by raising of the possessor out of the subject of the resultative, stranding the possessee. The stranding occurs independent of nonprimary predication constructions, as seen in (60b) and (61b).

(60) a. Lao Wang de fuqin si-le.

Lao Wang MOD father die-PRF

'Lao Wang's father died.'

b. Lao Wang si-le fuqin.

c. *Lao Wang si-le xiao gou.

Lao Wang die-PRF small dog

(61) a. Akiu de yi tiao tui duan-le.

Akiu MOD one CL leg broken-PRF

'One of Akiu's legs was broken.'

b. Akiu duan-le yi tiao tui.

\footnotetext{
${ }^{8}$ If case is related to event structure (Svenonius, this volume), and if the presence of a resultative has an effect on the event structure, the change of case in the following Icelandic data (see Svenonius, this volume, section 5) is accounted for. In these data, the verbs which take affected objects in the accusative take dative objects instead when they are combined with a resultative particle that indicates the object is moved to a different location:

$\begin{array}{llll}\text { (i) a. } & \text { Hann mokar snjó. } & \text { a'. } & \text { Hann mokar snjónum burt. } \\ & \text { he shovels snow.ACC } & & \text { he shovels the.snow.DAT away } \\ \text { b. } & \begin{array}{l}\text { Hann sópar gólfið. } \\ \text { he sweeps the.floor.ACC }\end{array} & \text { b'. } & \begin{array}{l}\text { Hann sópar ruslinu saman. } \\ \text { he sweeps the.gabage.DAT together }\end{array}\end{array}$
}


c. *Akiu duan-le yi tiao zhuozi-tui.

Akiu broken-PRF one cl table-leg

As shown in the c-forms, if there is no inalienable possession relation, the splitting between possessor and possesee is impossible. We leave the exact computation of the construction such sentences as an open issue. The possible analysis of the b-sentences of (60) and (61), especially the additional case-licensing of the possessee, should be extended to (59). Among possible choices are lexical case and default case. The special case-licensing should also be applied to the independent subject of the depictives in (12b) and (12c), and man-tou 'whole head' in (43). We thus do not consider data like $(59) /(12)$ as a challenge to our hypothesis of nonprimary selection.

\subsection{Comments on the "Strong-Weak Resultative" Approach}

It needs to point out that the PrP Theory provides no account for the violation of the c-/sselection of verbs in the presence of a complement-type nonprimary predicate.

Following Washio (1997), Wunderich (2000) claims that cross-linguistically, resultatives are divided into weak resultatives, in which a result sate already implied by the verb is specified more narrowly; and strong resultatives, in which some result state predicating of one of the involved participants of a process is added.

These two types of resultative construction are illustrated in (62) and (63).

(62) Weak resultatives
a. The children ran into the woods.
b. Peter cut the meat into slices.
c. The vase broke into several pieces.

(63) Strong resultatives

a. The children ran the lawn flat.

b. John drank the guests under the table.

c. The guests drank the wine cellar empty.

d. He ran himself tired.

The assumed contrasts between strong and weak resultatives are listed in (64) in Wunderich (2000):

\begin{tabular}{|c|c|c|c|}
\hline \multicolumn{2}{|c|}{$(64)$} & strong & weak \\
\hline I & A new individual argument is introduced & yes & no \\
\hline II & AP result predicates are possible & yes & no \\
\hline III & $\begin{array}{l}\text { The result predicate can specify a change which is not inherent to the } \\
\text { meaning of the base verb }\end{array}$ & yes & no \\
\hline IV & An independent subevent is added & yes & no \\
\hline
\end{tabular}

Our first comment on this classification is that if verbs of creation are considered, the division is not so clear-cut.

(65) He drew her face square.

In (65), the resultative is an AP, so it patterns with the strong type (II). However, patterning with the weak type, no new individual argument is introduced (I), and no 
independent subevent is added (IV). Moreover, it is not clear whether the result predicate specifies a change which is not inherent to the meaning of the base verb (III).

Our second comment on this classification is that it is not true that cross-linguistically the negative value of both III and IV is corespondent to the negative value of II. In Chinese, the object-oriented resultatives which occur with verbs of change of state and creation not only can, but also must, be AP (the positive value of II). Such resultatives pattern with the weak type in not adding an independent subevent (IV). For those occurring with verbs of change of state, clearly no change which is not inherent to the meaning of the base verb is specified (III). We have introduced the AP-data in (32a) and (34a). PP-resultatives are not allowed here because of the language-specific nonprimary c-selection.

The contrast between the resultative reading of AP nonprimary predicate with verbs of change of state in Chinese and the depictive reading of AP nonprimary predicate with the same type of verbs in English, as shown in (39) through (41), is an s-selection contrast of the type of verbs between the two languages, as we claimed before.

We conclude that the syntax-semantics mapping claimed by this Strong-Weak Resultative Approach is not accurate. Our hypothesis of nonprimary selectional restrictions can better capture both cross-linguistic and language-internal variations.

\section{C-Selection Violation and the So-Called "Direct Object Restriction"}

In this section we argue that the orientation of nonprimary predicate, i.e., the interpretation of the subject of the $\mathrm{xP}$ in (4), is syntactically decided, and our analysis in turn explains the following type of obligatory c-selection violation in the presence of a resultative:

(66) a. The lion gnawed *(on) the bone.

b. The lion gnawed (*on) the bone raw.

\subsection{A Syntactic Account for the "Direct Object Restriction"}

It has long been claimed that resultatives must be object-oriented. The constraint is called Direct Object Restriction (DOR) in Leven and Rappaport-Hovav (1995:34). We argue that DOR is an economy effect of syntax, rather than a semantic constraint on resultatives (contra Rothstein 2001 and many others).

First, there are two constructions where resultatives are hosted by complement of the verb in Chinese: the de-construction and the V-V construction. DOR is present only in the former, not the latter, as extensively discussed in the literature (Li 1990, 1998, Huang 1992, etc.). The contrast is shown in (67) and (68). In the second reading of (67a), the resultative is subject-oriented, a violation of DOR: ${ }^{9}$

(67) a. Baoyu zhui lei le Daiyu.

Baoyu chase tired PRF Daiyu

'Baoyu chased Daiyu and as a result Daiyu got tired.'

'Baoyu chased Daiyu and as a result Baoyu got tired.'

b. Baoyu zhui de Daiyu qichuanxuxu.

Baoyu chase DE Daiyu gasp

'Baoyu chased Daiyu and as a result Daiyu gasped.'

(68) a. Baoyu kan ni le na pan luxiang.

Baoyu watch fed.up PRF that CL video

'Baoyu watched that video and as a result he got fed up with it.'

\footnotetext{
${ }^{9}$ The subject of the primary predicate of (67a) can also be a theme causer. In that case, the reading of the sentence is 'Chasing Baoyu, Daiyu got tired.' See Zhang (2001a) for a discussion.
} 
b. *Baoyu kan de na pan luxiang dou ni le. Baoyu watch DE that CL video even fed.up PRF

In the V-V construction (67a), the subject of the resultative predicate is co-referential with either the subject or the object of Vpri, i.e., either Baoyu or Daiyu got tired. However, in the $d e$ construction (67b), the subject of the resultative predicate can only be co-referential with the object of Vpri, i.e., only Daiyu gasped, not Baoyu. In the V-V construction (68a), the subject of the resultative predicate is co-referential with the subject of Vpri, i.e., Baoyu got fed up. It cannot be co-referential with the object of Vpri, since semantically, na pan luxiang 'that video' cannot be the subject of the predicate $n i$ 'get fed up'. In the de construction (68b), the subject of the resultative predicate cannot co-referential with the subject of Vpri. It can only be co-referential with the object of Vpri. However, since the semantic clash mentioned above rules out the co-indexing, the secondary predication fails and the sentence is unacceptable.

Second, resultatives which occur in an adjunct position, i.e., pre-Vpri, do not have DOR. In (69), baobao 'full' is a subject-oriented resultative.

Akiu baobao de chi-le yi dun nian-ye-fan.

Akiu full DE eat-PRF one CL year-night-meal

'Akiu ate a New-Year-eve-meal so that he became full.'

Third, depictives also have DOR, if they occur to the right of de, the same position where resultatives occur and DOR applies (cf. (67b))

(70) a. Lao Wang hen xingfen de mai-le na jian chenshan.

Lao Wang very excited DE buy- PRF that CL shirt

'Lao Wang bought that shirt very excited.'

b. $\quad \mathrm{Na}$ jian chenshan, Lao Wang mai de $\{$ *hen xingfen/tai da le $\}$.

that CL shirt Lao Wang buy DE very excited/too big PRT

'That shirt, Lao Wang bought, and it is too big.'

In (70a) the subject-oriented depictive hen xingfen 'very excited' can occur in the adjunct position (i.e., pre-Vpri), but not the complement position (i.e., post-Vpri). The objectoriented depictive tai da le 'too big', however, can occur in the complement position. The contrast between hen xingfen and tai da le in (70b) is the effect of DOR, although the nonprimary predicates are depictives rather than resultatives.

What we have shown so far is that DOR applies only when the nonprimary predicate occurs to the right of $d e$. Syntactically, the relevant condition for the presence of DOR is the following: either there is no head movement from the nonprimary predicate to the primary one, if the former belongs to the complement-type, or the nonprimary predicate belongs to the adjunct type (the subject-oriented depictives in English and preverbal resultatives/depictives in Chinese).

Based on this observation, we make the following generalization: only in the complement-type, and only when no head movement occurs, regardless of whether the nonprimary predicate is resultative or depictive, DOR occurs.

We claim that the head movement in the V-V construction has the effect of restructuring, and DOR is an effect of the syntactic locality constraint on the constructions where there is no restructuring. Specifically, in the absence of a restructuring, as in the Chinese de-construction and other chain-type constructions, including the resultative constructions in English, the PRO subject of the resultatives is controlled by the nearest overt 
c-commanding argument of the primary predicate, i.e., the direct object, rather than the subject. The Chinese V-V constructions, however, have undergone restructuring and thus the control domain is changed. Consequently, either the overt direct object or the subject of the primary predicate can control the PRO subject of the nonprimary predicate. As for nonprimary predicates which are hosted by adjuncts, their control patterns are the same as that of adverbials (Hornstein \& Lightfoot 1987, Hornstein 2001), i.e., the PRO can be either subject-controlled or object-controlled, depending on the merger position of the $\mathrm{xP}$. Therefore, such predicates can be either subject-oriented or object-oriented.

\subsection{One More Instance of Obligatory C-Selection Violation}

Our syntactic analysis of DOR accounts for one more case of c-selection violation in the presence of nonprimary predicate. Kim and Maling (1997) present the following contrast:

(71) a. The lion gnawed *(on) the bone.

b. The lion gnawed (*on) the bone raw.

(72) a. The winemakers stomped *(on) the grapes.

b. The winemakers stomped (*on) the grapes flat.

(73) a. The professor lectured *(to) the class.

b. The professor lectured (*to) the class into a stupor.

In the a-sentences above, the verb c-selects the PP rather than the DP. The c-selection, however, is not seen in the b-sentences, where a resultative occurs. Crucially, in the bsentences, the theme of the verb is the antecedent of the subject of the resultative. This effect is achieved by DOR. Specifically, the theme is the nearest overt c-commanding nominal, and is able to control the PRO subject of the resultative. If the preposition shows up, the theme becomes the object of the preposition, and thus does not c-command the PRO. In that case, the control fails. This is covered by the observation that the subject of a secondary predicate cannot be co-referential with the object of a preposition (Williams 1980: 204). For instance, the subject of the resultative predicate full is co-referential with the object of the Vpri, wagon, in (23a); however, the subject of full cannot be co-referential with wagon, which is the object of the preposition into, in (23b). Similarly, the subject of the depictive predicate green cannot be co-referential with hay, which is the object of the preposition with, in (23d).

(74) a. John loaded the wagon full [with hay].

b. $\quad *$ John loaded the hay [into the wagon] full.

c. John loaded the hay [into the wagon] green.

d. *John loaded the wagon [with hay] green.

The contrast in (71) through (73) is explained: the PRO in $\mathrm{xP}$ forces the selecting verb to bend its c-selection. Why is the nonprimary predication so powerful? The reason is that in the presence of the $\mathrm{xP}$ which encodes the nonprimary predication in the working site, the verb is merged with the $\mathrm{xP}$ first, and has to accommodate itself to the required syntactic conditions. In this sense, our nonprimary selectional restrictions can be regarded as selectional restrictions on preliminary merge of lexical heads with a predication-denoting element.

\section{Conclusions}

All of the above syntactic/semantic variations, constraints, and the "selectionviolations" in the presence of nonprimary predicates are simply the effects of the nonprimary selectional restrictions on the merge of verbs with a functional projection which denotes a predication relation. It is doubtful whether pure semantic and constructional approaches can 
capture the interactions and variations. We conclude that all types of thematic predication are represented by an extended projection, and that the merger of lexical heads with another element, regardless of the type of the element, consistently has c- and s-selectional restrictions.

\section{Appendix: the Obligatory Object-Preposing}

In Chinese, certain types of verbs require their complement-type nonprimary predicates to be APs, and for these verbs, their objects must be preposed in the de-construction. We call this obligatory object-preposing OOP. OOP is seen in verbs of change of state (32a vs. 32b), transference (33a vs. 33b), and creation (34a vs. 34b), in contrast to other types (35). Relevantly, postverbal manners must be APs, and objects must also be preposed in the deconstruction (36).

However, for the same range of verbs (creation, change of state, transference verbs for non-manner predicates and all verbs for manner predicates), OOP is absent in two cases. First, adjunct-type (i.e., preverbal ones) of nonprimary predicates which are integrated with the same types of verbs do not require OOP:

(75) a. Akiu hen jian de xue-le $\{$ yi/*na $\}$ zhi qianbi.

Akiu very sharp DE cut-PRF one/that CL pencil

'Akiu cut a pencil sharp.'

b. Baoyu chendiandian de linlai-le $\{\mathrm{yi} / *$ na $\}$ bao lipin.

Baoyu heavy DE bring-PRF one/that package gift

'Baoyu brought a package of gift heavy.'

c. Baoyu dada de xie-le $\{$ jige/*naxie $\}$ zi.

Baoyu big DE write several/those character

'Baoyu wrote several characters big.'

d. Akiu feikuai de nian-le $\{\mathrm{yi} / \mathrm{na}\}$ shou shi.

Akiu fast DE read-PRF one/that CL poem

'Akiu read $\{a /$ that $\}$ poem fast.'

One important property of this construction is that the shared argument, which is the post-verbal object in the non-manner constructions, must be nonspecific. We will discuss this property soon.

Second, OOP is not see in the V-V construction, as shown in (76).

(76) a. Akiu xue-jian-le yi zhi qianbi.

Akiu cut-sharp-PRF one CL pencil

'Akiu cut a pencil sharp.'

b. Baoyu mai-da-le yi jian chenshan.

Baoyu buy-big-PRF one CL shirt

'Baoyu bought a shirt over-sized.'

c. Baoyu xie-da-le yi ge zi.

Baoyu write-big-PRF one CL character

'Baoyu wrote a character over-sized.'

d. Akiu kou-yi-le $\quad$ yi/na $\}$ tiao xiaoxi.

Akiu oral-translate-PRF one/that CL news

'Akiu translated $\{\mathrm{a} /$ that $\}$ piece of news orally.'

One contrast between the data where OOP is present and those where OOP is absent is that the event denoted by the primary predication is presupposed in the former, but not in the 
latter. In both types of data where OOP is absent ((75) and (76)), the event denoted by the primary predication is not presupposed, whereas in the cases where OOP is present $(32,33$, 34,36 ), the event denoted by the primary predication is presupposed. In the former case, the nonprimary predicates "restrict" the range of events referred to, whereas in the latter case, the nonprimary predicates take verbal reference for granted and say something about the event (if the nonprimary predicate is a manner expression), or the object (if the nonprimary predicate is not a manner expression) designed by the primary predicate.

This claim of the presupposition contrast is supported by our observation of both the de-construction and the $\mathrm{V}-\mathrm{V}$ construction. In the de-construction where the nonprimary predicate is hosted by an adjunct, as in (75), the shared argument cannot be specific. We have already seen that in (75), the shared argument cannot be definite. In (77), we show that the shared argument cannot be in the order of "Modifier-Numeral-Classifier-N," which is argued to be exclusively presupposed specific in Zhang (2001b):

(77) a. Akiu hen jian de xue-le \{san zhi hongse de/*hongse de san zhi $\}$ qianbi. Akiu very sharp DE cut-PRF $\{$ three CL red de/red DE three CL $\}$ pencil 'Akiu cut three red pencils sharp.'

b. $\quad$ Akiu feikuai de nian-le $\{$ liang shou hen chang de/hen chang de liang shou $\}$ shi. Akiu fast DE read-PRF \{ two CL very long DE/very long DE two CL poem 'Akiu read two long poem fast.'

In (77a) the shared argument is 'three red pencils.' The internal order of the indefinite nominal causes the acceptability difference. In (77b), however, there is no shared argument between the two predication, since the manner expression takes the event denoted by the primary predication as subject. In this case, both orders of the object are fine.

In the V-V construction in (76), the shared argument can be specific or definite only when the whole sentence is followed by another sentence, as in (78).

a. Akiu xue-jian-le na zhi qianbi, \#(jiu kaishi xie xin). Akiu cut-sharp-PRF that CL pencil then start write letter

'Akiu cut that pencil sharp and then started to write a letter.'

b. Akiu mai-da-le na jian chenshan, \#(lai wen wo zemeban).

Akiu buy-big-PRF that CL shirt then ask I how.do

'Akiu bought that shirt oversized and then asked me what to do.'

In (78), when the V-V sentence is followed by another sentence, it occurs as a background rather than a foreground sentence.

OOP thus seems to be related to a presupposition of the event denoted by the primary predication. At this moment, we have no syntactic account for the OOP effect.

Data of verbs of change of state, like (75a) and (76a), are analyzed as manners, rather than regular resultatives, in Washio (1997: 19). We have shown that they share syntactic properties with not only manners but also the object-oriented nonprimary predicates which occur with verbs of creation and transference. It is very counter-intuitive to view the latter group of nonprimary predicates as manners. For instance, in (76b), the nonprimary predicate $d a$ 'big, oversized' is hardly considered as a manner of buying. We thus need a different approach to such data, in order to explain OOP

\section{References}

Aoun, J., E. Benmamoun, and d. Sportiche 1994 Agreement and conjunction in some varieties 
of Arabic. Linguistic Inquiry 25, 195-220.

Aoun, J., E. Benmamoun, and d. Sportiche 1999 Further remarks on first conjunct agreement, Linguistic Inquiry 30, 669-681.

Borsley, R. 2001 Against ConjP. Handout distributed at the $4^{\text {th }}$ NWCL International

Conference: Coordination: Syntax, Semantics, and Pragmatics, Nov. 16-18.

Bowers, J. 1993 The syntax of predication. Linguistic Inquiry 24, 591-656.

Bowers, J. 1997 A binary analysis of resultatives. Texas Linguistics Forum 38, 43-58.

Bowers, J. 2001 Predication. M. Baltin \& C. Collins (eds.) The Handbook of Contemporary Syntactic Theory. Blackwell. 299-333.

Carrier, J. \& J. Randall 1992 The argument structure and syntactic structure of resultatives. Linguistics Inquiry 23, 173-234.

Chomsky, N. 1995 Categories and transformation. In The Minimalist Program, 219-394. Cambridge, Mass.: MIT Press.

Dechaine, R-M. 1993 Predicates Across Categories: Towards Category-neutral Syntax. Doctoral Dissertation. University of Massachusetts, Amherst.

den Dikken, M. \& R. Sybesma 1998 Take Serials Light up the Middle. Paper presented at GLOW 21, Tilburg University, 15 April 1998.

Diesing, M. 1992 Indefinites, MIT Press, Cambridge, MA.

Ernst, T. 1996 Chinese evidence for semi-arguments. Studies in the Linguistic Sciences 26, Department of Linguistics, University of Illinois at Urbana-Champaign. 117-132.

Ernst, T. 1999 Manners and Events. C. Tenny \& J. Pustejovsky (eds.) Events as Grammatical Objects, CSLI, Stanford. 335-358.

Grimshaw, J. 1992 Extended projection. Ms. Brandeis University.

Grimshaw, J. 1994 Minimal projection and clause structure. In B. Lust, M. Suner, and J. Whitman (eds.) Syntactic Theory and First Language Acquisition: Cross-Linguistic Perspectives, Vol. 1. Lawrence Erlbaum Associates, Publishers, New Jersey.

$\mathrm{Gu}$, Yang 1992 The syntax of resultative and causative compounds in Chinese. PhD. Dissertation, Cornell University.

Heim, I. \& A. Kratzer 1998 Semantics and Generative Grammar, Blackwell.

Heycock, C. 1993 Syntactic Predication in Japanese. Journal of East Asian Linguistics 2, 167211.

Heycock, C. \& E. Doron 2001 The recursion of predication. Abstract selected by the Workshop on Syntax of Predication. ZAS-Berlin. Nov. 2-3. http://www.zas.gwzberlin.de/events/predication/index.html

Hoekstra, T. 1988 Small Clause Results. Lingua 74, 101-139.

Hoekstra, T. 1992 Aspect and Theta Theory. Thematic structure: Its role in grammar, ed. by I. M. Toca. 145-174,. Berlin: Foris.

Hornstein, N. 1999 Movement and Control, Linguistic Inquiry 30, 69-96.

Hornstein, N. 2001 Move! A Minimalist Theory of Construal. Blackwell, Massachusetts.

Hornstein, N. \& D. Lightfoot 1987 Predication and PRO. Language 63: 23-52.

Huang, J. 1988 Wo Pao De Kuai and Chinese Phrase Structure, Language 64, 274-311.

Huang, J. 1992 Complex Predicates in Control. In J. Higginbotham and R. Larson (eds.), Control and Grammar, Kluwer, Dordrecht, 109-147.

Kayne, R. 2001 Pronoun and their Antecedents. Ms. http://minimalism.linguistics.arizona.edu.../AMSA-190-0601.htm

Kim, S. \& J. Maling 1997 A crosslinguistic perspective on resultative formation. Texas Linguistics Forum 38, 189-204.

Koizumi, M. 1994 Secondary Predicates. Journal of East Asian Linguistics 3, 25-79.

Kratzer, A. 1994 On External Arguments. University of Massachusetts Occasional Papers 17: 103-130. 
Larson, R. 1991 Some issues in verb serialization. Serial verbs: grammatical, comparative and cognitive approaches, edited by C. Lefebvre, 185-210. John Benjamins, Amsterdam.

Levin, B. and M. Rappaport Hovav 1995 Unaccusativity: At the Syntax-Lexical Semantics Interface. Cambridge, Mass: MIT Press.

Li, A. 1999 Minimal $\alpha$. Paper presented at DGfS 21, Konstanz, February 24.

Li, C. \& S. Thompson 1981 Mandarin Chinese: a functional reference grammar. University of California Press, Berkeley/Los Angeles.

Li, Y. 1990 On V-V compounds in Chinese. Natural Language and Linguistics Theory 8, 177-207.

Li, Y. 1998 Chinese Resultative Constructions and the Uniformity of Theta Assignment Hypothesis. In: J. Packard (ed.) New Approaches to Chinese Word Formation. Mouton de Gruyter, Berlin, 285-310.

Li, Y. 1999 Cross-componential causativity. Natural Language and Linguistic Theory 17: 445-497.

Lóbez, Luis, 2001 Head of a Projection, Linguistic Inquiry 32, 521-532.

Lü, S. et al. 19801/1999 Xiandai Hanyu Babai Ci [800 Words in Chinese]. Shangwu Press.

Marantz, A. 1997 No escape from syntax: don't try morphological analysis in the privacy of your own lexicon. U. Penn Working Papers in Linguistics, 4-2, 201-225.

McConnell-Ginet, S. 1982 Adverbs and logical form: a linguistically realistic theory. Language 58, 144-184.

Munn, A. 1999 First conjunct agreement: Against a clausal analysis. Linguistic Inquiry 30, 643-668.

Nishiyama, K. 1998 V-V Compounds as Serialization. Journal of East Asian Linguistics 7, 175-217.

Odijik, J. 1997 C-Selection and S-Selection. Linguistic Inquiry 28, 365-391.

Pesetsky, D. 1995 Zero Syntax. MIT Press

Rapoport, T. R. To appear. The predicate in aspectual representation. In H. Bennis \& M. Everaert (eds.) Interface Strategies. KNAW.

Roberts, I. 1988 Predicative APs.Linguistic Inquiry 19, 703-10.

Rosenbaum, P. 1970 A Principle Governing Deletion in English Sentential Complementations. In R. Jacobs and P. Rosenbaum (eds.) Readings in English Transformational Grammar, Ginn, Waltham, MA, 20-9.

Rothstein, S. 1985 The syntactic forms of predication. Ph. D. dissertation. MIT.

Rothstein, S. 1992 Case and NP licensing. Natural Language and Linguistic Theory 10, 119139.

Rothstein, S. 2000a Secondary predication and aspectual structure. ZAS Papers in Linguistics $17,242-264$.

Rothstein, S. 2000b Deriving restrictions on resultatives: incrementality, culminations, and result states. Paper presented at the Workshop on Predicative Constructions, ZAS, Berlin, Oct. 16-17.

Rothstein, S. 2001 What are Incremental Themes? ZASPIL 22, 139-157.

Schütze, C. 2001 On the nature of default case. Syntax 4, 205-238.

Simpson, J. 1983 Resultatives. L. Levin, M. Rappaport \& A. Zaenen (eds.) Papers in LexicalFunctional Grammar, 143-157. Bloomington, Indiana University Linguistics Club.

Speas, P. 2000 Re: c-selection and s-selection as introduced by Culicover in Principles and Parameters Theory, and what further elaboration on the plausibility of DP theory. http://www.linguist.org/ ask-ling/archive-most-recent/msg02747.html

Strigin, A. and A. Demjjanow 2001 Secondary Predication in Russian. ZASPIL 25, 1-79. 
Svenonius, P. 1995 Dependent Nexus: Secondary Predication in English and the Scandinavian Languages. Abstract of PhD dissertation, Glot International 1, Issue 9/10. Sybesma, R. 1999 The Mandarin VP. Kluwer Academic Publishers: Dordrecht.

Talmy, L. 1991 path to realization: A typology of event conflation. Proceedings of the Berkeley Linguistic Society 17, 480-519.

Vanden Wyngaerd, Guido 2001 Measuring Events. Language 77, 61-90.

Veenstra, T. 1996 Serial Verbs in Saramanccan: Predication and Creole Genesis. Den Haag: Holland Acadamic.

Washio, R. 1997 Resultatives, compositionality and language variation. Journal of East Asian Linguistics 6, 1-49.

Williams, E. 1980 Predication. Linguistic Inquiry 11, 203-238.

Williams, E. 1985 PRO and subject of NP. Natural Language and Linguistic Theory 3, 297315.

Williams, E. 1997 Lexical and syntactic complex predicates. A. Alsina, J. Bresnan \& P. Sells (eds) Complex Predicates, 13-28. CLSI Publications.

Wunderich, D. 2000 Predicate composition and argument extension as general options. In Barbara Stiebels and Dieter Wunderlich (eds.) Lexicon in Focus, 247-270. Berlin: Akademie Verlag (= studia grammatica 45 )

Zhang, N. 1997 Syntactic dependencies in Mandarin Chinese. PhD dissertation, University of Toronto.

Zhang, N. 2001a The structures of depictive and resultative constructions in Chinese. ZASPIL 22, 191-221.

Zhang, N. 2001b Representing specificity by the internal order of indefinites. Ms. ZASBerlin. 